\title{
Effective voltage flicker calculation algorithm using indirect demodulation method
}

\author{
C.J. Wu and T.H. Fu
}

\begin{abstract}
The voltage flicker is one of the major power quality disturbances in a weak power system. Better measurement and limitation techniques are always desired. An effective and accurate calculation method is presented to obtain the voltage flicker components and the $10 \mathrm{~Hz}$ equivalent value. By using the indirect demodulation method, the RMS values of a voltage waveform are calculated cycle by cycle to obtain the envelope. Then the fast Fourier transform (FFT) is used to obtain the flicker components. This method can increase the computing speed and reduce the hardware requirement in a power quality instrument when the FFT is used. The effects of sampling rate, harmonics, and system frequency shifting are investigated. The latter two are common disturbances in addition to the voltage flicker when arc furnace loads are connected in a weak power system. A calibration procedure is used to improve the frequency leakage effect and increase the calculation accuracy. The calculation results from given voltage flicker waveforms and field measured waveforms reveal the effectiveness of the proposed method. It can be used in both 50 and $60 \mathrm{~Hz}$ systems.
\end{abstract}

\section{List of symbols}

$f_{n}$
$f_{s}$
$f_{s y s}$
$G_{A}$
$G_{C}$
$H$
$h$
$M$
$N$
$T$
$V[k]$
$V_{\text {aterage }}$
$v(t)$
$v_{m m s}(t), v_{\text {mms }}[i]$
$v_{s}(t), v_{s}[i]$
$\Delta V$
$\Delta V 10$
$\Delta V_{-n}$

flicker modulation frequency sampling frequency power frequency attenuation factor calibration factor number of RMS values (number of windows)

jump-sampling number

number of total sampled data

sampled data number of a cycle

total sampling duration

frequency spectrum magnitude by FFT average of RMS values

instantaneous voltage

RMS value of a window

profile of RMS values

voltage deviation

voltage flicker $10 \mathrm{~Hz}$ equivalent value magnitude modulation component of frequency $f_{n}$

\section{Introduction}

Fluctuating loads, such as electric arc furnaces and arc welders, may cause the disturbances of voltage flicker

(c) IEE, 2003

IEE Proceedings online no. 20030302

doi:10.1049/ip-gtd:20030302

Publication date: 10th April 2003. Paper first received 15th April 2002 and in revised form 9th January 2003

The authors are with the Department of Electrical Engineering, National Taiwan University of Science and Technology, PO Box 14-56. Peitow-Taipei 112 , Taiwan (voltage fluctuation) in a weak power system and affect the illumination in nearby distribution areas. For an arc furnace in the melting stage, load currents change continuously and extremely. If the system short-circuit capacity is not large enough, the voltage drop in the feeder line will change obviously and irregularly [1]. Many reports indicate that a small voltage flicker from $0.3 \%$ to $0.5 \%$ in the frequency range of $6-10 \mathrm{~Hz}$ will cause visible incandescent lamp flickering $[2,3]$ and make people feel uncomfortable. The power system in Taiwan is an island system. Voltage flicker problems have appeared in several distribution areas of the Taiwan Power Company for a long time $[4,5]$. Voltage flicker is considered to be one of the major power quality disturbances [6].

In evaluation and limitation, there are some definitions and standards to quantify the voltage magnitude variation levels, such as IEEE 519-1992 and IEC 61000 [7-9]. Many measurement techniques and equipments have been studied and applied $[10,11]$. In order to evaluate the level of voltage fluctuation correctly, the definition of voltage-flicker severity was proposed and a standard meter was also developed by the Disturbance Committee of the International Union for Electroheat (UIE), in cooperation with the International Electrotechnical Commission (IEC) [12]. The voltage-flicker severity is expressed as short-term severity, $P_{s t}$, and long-term severity, $P_{l l}$. The values recommended by IEC 61000-3-3 [8] and IEC 61000-3-5 [9], are $P_{s t}=1.0 \mathrm{pu}$ and $P_{l t}=0.65 \mathrm{pu}$, with a nominal voltage fluctuation less than $3 \%$ and a maximum voltage fluctuation less than $4 \%$, for a $220-250 \mathrm{~V}$ (to neutral point voltage) low-voltage system.

The voltage flicker $10 \mathrm{~Hz}$ equivalent value, $\Delta V 10$, is used by some Asian utilities $[13,14]$ to represent the severity of voltage flicker and to evaluate customers with fluctuating loads. This method converts all amplitude modulation components (flicker components) of the waveform into the $10 \mathrm{~Hz}$ equivalent value to represent the equivalent effect. Each flicker component has a different weighting value. In order to obtain the flicker components, methods based on 
the discrete Fourier transform (DFT) or the fast Fourier transform (FFT) can be used. If the DFT or FFT is carried out directly for the sampled data of a voltage waveform in a specified duration, it is called the direct demodulation method (DDM) [15]. The flicker components can be obtained from the frequency spectrum. Although this method is simple, the difficulty is that the sampled data size should be extremely large considering the resolution. This increases hardware requirement in a power quality instrument. The indirect demodulation method (IDDM) is an alternative. First, the RMS values of the sampled voltage waveform are calculated cycle by cycle to obtain the waveform envelope. Then the FFT is carried out with data from the envelope to obtain the flicker components. The data size can be small. The benefits are higher computing speed and less instrument hardware requirement.

The IDDM is used in this paper to calculate voltage ficker components and the $10 \mathrm{~Hz}$ equivalent value. The effects of sampling methods and data length are considered. In order to improve the frequency leakage effect (side-lobes effect) in the FFT, a calibration procedure is given. The calculation results from given voltage flicker waveforms and field measured waveforms show that the method is effective and accurate. This method also can sustain the influences of harmonics and system frequency shifting.

\section{Voltage flicker}

At steady state without any disturbance, the voltage waveform in a power system is sinusoidal with constant amplitude. However, the operation of fluctuating loads, such as electric arc furnaces, would cause disturbances of voltage flicker in the neighbouring power system. For a short duration, a voltage flicker waveform [15] can be described as

$$
\begin{aligned}
v(t)= & s(t) \sin \left(2 \pi f_{s y s} t\right) \\
= & \sqrt{2} V_{m s}\left[1+\frac{1}{2} \sum_{n} \Delta V_{\lrcorner n} \sin \left(2 \pi f_{n} t+\varphi_{n}\right)\right] \\
& \times \sin \left(2 \pi f_{s y s} t\right)
\end{aligned}
$$

where $f_{s y s}$ is the power frequency ( 50 or $60 \mathrm{~Hz}$ ), $V_{r m s}$ is the average RMS value of the voltage, and $\Delta V_{n}$ is the amplitude modulation value of the modulation frequency $f_{n}$. Expression (1) is an amplitude modulation (AM) function with the signal $s(t)$ and the carrier frequency $f_{s y s}$. For voltage flicker limitation, we usually consider $f_{n}$ in the range $0.1 \mathrm{~Hz} \sim 30 \mathrm{~Hz}$ only. Fig. 1 shows a simplified voltage flicker waveform, which contains one

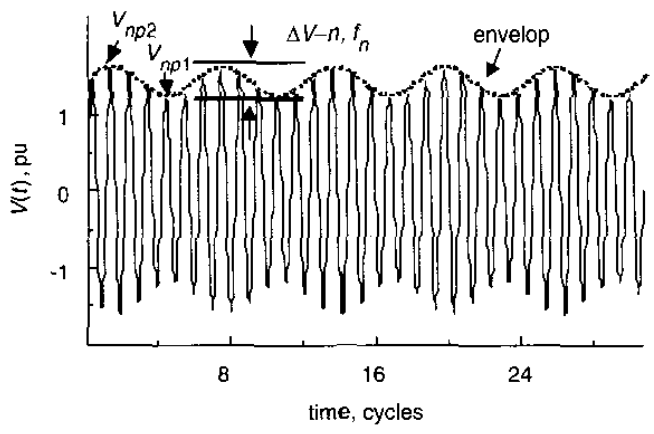

Fig. 1 Voltage flicker waveform with $\Delta V_{n}=0.3 p u$ and $f_{n}=10 \mathrm{~Hz}$

494 modulation component with $\Delta V_{-n}=0.3 \pi$ and $f_{n}=10 \mathrm{~Hz}$. Under simple circumstances with only one modulation component, the voltage variation in Fig 1 can be expressed as [16]

$$
\Delta V_{n}=V_{n p 2}-V_{n p 1}
$$

However, a voltage flicker waveform usually contains many modulation components, and therefore the practical voltage variation $\Delta V$ can be expressed as [4]

$$
\Delta V=\sqrt{\sum_{n}\left(\Delta V_{-n}\right)^{2}}
$$

The voltage flicker $10 \mathrm{~Hz}$ equivalent value $\Delta V 10$ is

$$
\Delta V 10=\sqrt{\sum_{n}\left(a_{n} \Delta V_{-n}\right)^{2}}
$$

The flicker sensitivity coefficient $a_{n}$, as a function of flicker frequency $f_{n}$, is shown in Fig. 2 which describes the sensitivity of man's eye-brain mechanism to illumination flicker. The method using $\Delta V 10$ is used by the Taiwan Power Company for voltage flicker limitation [14].

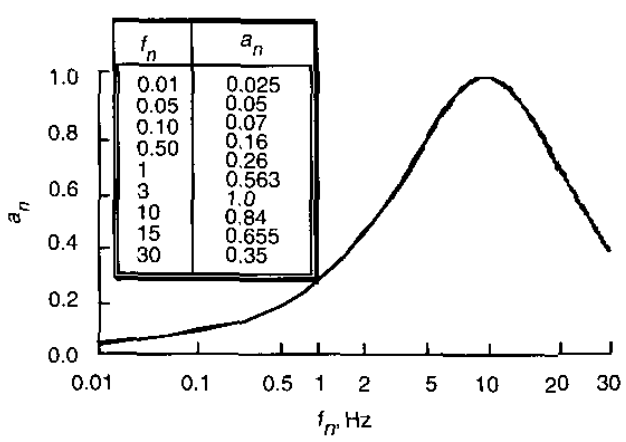

Fig. 2 Flicker sensitivity coefficient curve

\section{Voltage flicker calculation method}

The requirement is to obtain the frequency components of the signal $s(t)$ in (1). This is a general demodulation procedure. The indirect demodulation method (IDDM) is used in this Section. The flowchart is shown in Fig 3. Fig. 4 shows the concept of data handling. A simple illustration is given in Fig. 5.

The moving window method is used to calculate the RMS values of the instantaneous voltage $v(t)$ with $N$ samples in each cycle as a window as shown in Fig. $5 a$. Then it is shifted $h$ samples (jump-sampling) to reach the next window. At window $i$, the RMS value is

$$
\begin{aligned}
& v_{m s}(t) \equiv v_{m s}[i]=\sqrt{\frac{\sum_{m=(i-1) h+1}^{(i-1) h+N} v^{2}[m]}{N}}, \\
& i=1,2, \ldots, H
\end{aligned}
$$

With a total of $H$ RMS values in $H$ windows, the envelope of the original waveform is obtained as shown in Fig. $5 b$. The average value of the RMS values within the measurement period is

$$
V_{\text {average }}=\left(\sum_{i=1}^{H} v_{r m s}[i]\right) / H
$$




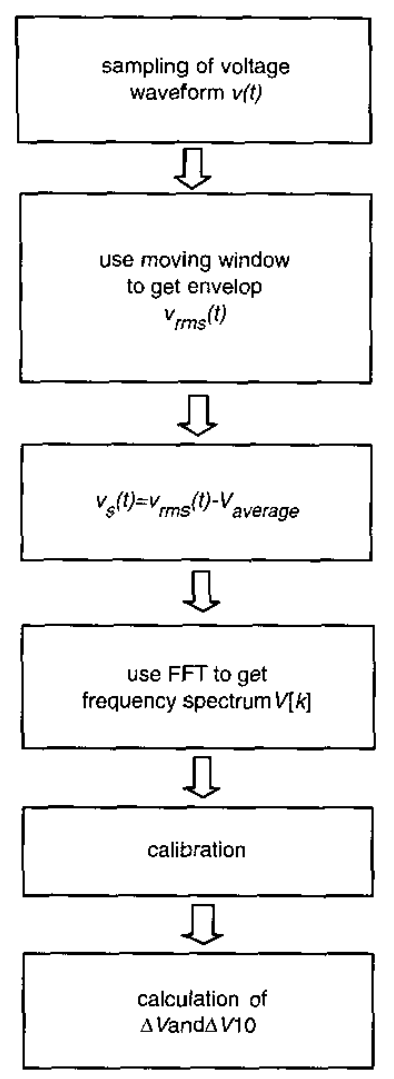

Fig. 3 Flowchart of the IDDM

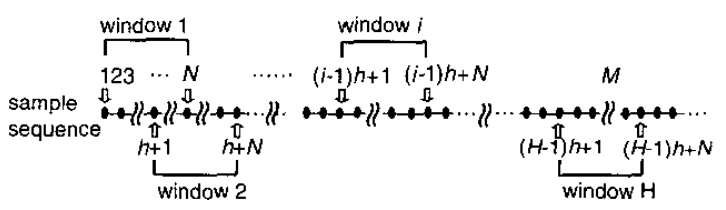

Fig. 4 Moving windov method to obtain RMS value of $v(t)$

Then the average value is subtracted from the RMS value in each window. Hence

$$
v_{s}(t) \equiv v_{s}[i]=v_{m s}[i]-V_{\text {aterage }}, \quad i=1,2, \ldots, H
$$

The final envelope is obtained as shown in Fig. $5 c$. The reason for subtracting the average value is that it will appear as a DC component in the frequency spectrum, which causes a spike and affects the accurate values of the nearby components.

The frequency components of $v_{s}[i]$ are the flicker components of $v(t)$. An FFT is used to calculate the frequency spectrum [17]. Thereby

$$
\begin{aligned}
V[k] & =\frac{1}{H} \sum_{i=1}^{H} v_{s}[i] \exp \left(-j \frac{2 \pi i}{H}\right) k, \\
k & =1,2, \ldots, H / 2
\end{aligned}
$$

Therefore the $f_{n} \mathrm{~Hz}$ amplitude modulation value in (1) can be obtained from the data sequence of $V[k][18]$, i.e.

$$
\Delta V_{n}=\frac{2 \sqrt{2}}{V_{\text {average }}} V\left[\frac{f_{n}}{\left(f_{s} / M\right)}\right] \times 100 \%
$$
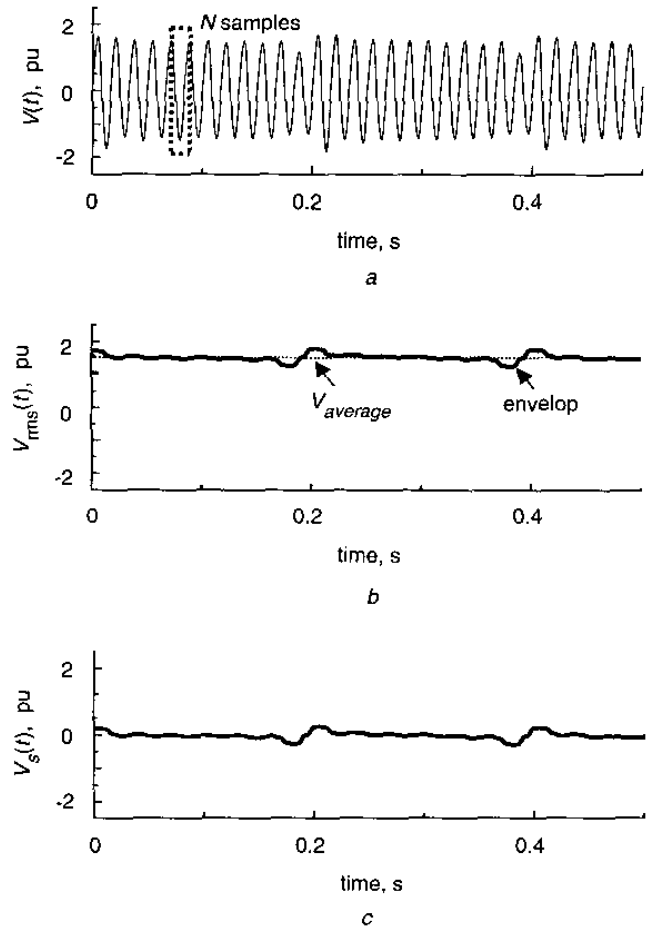

Fig. 5 Method used to obtain the envelope a $N$ samples in a window

$b$ Envelope curve of original waveform

$c$ Envelope curve of $b$ by subtracting the average value

where $f_{s}=\frac{M}{T}$ is the sampling frequency, and $M$ is the total sampling number within the total sampling duration $T$. The values of $\Delta V$ and $\Delta V 10$ can then be calculated.

From Fig. 4 and (5)-(8), it can be found that $M=h H=T N f_{s v s}=T f_{s}$. To use the FFT in (8), it is required that $H=2^{j}$ where $j$ is a positive integer, and so there should be special combinations of these parameters. It can be found that the choice of $h$ is limited. It is also noted that although $M$ data may be needed in the DDM, only $H$ data are used in the FFT of the IDDM. The number of data for the FFT can be as small as possible. The benefits are high computing speed and less instrument hardware requirement.

\section{Effect of sampling and data length}

In the spectrum calculation of $v_{s}[i]$ using FFT, the frequency resolution is $f_{s} / M$. Therefore, different $f_{s}, T$ or $N$ will give different $M$, and result in different frequency

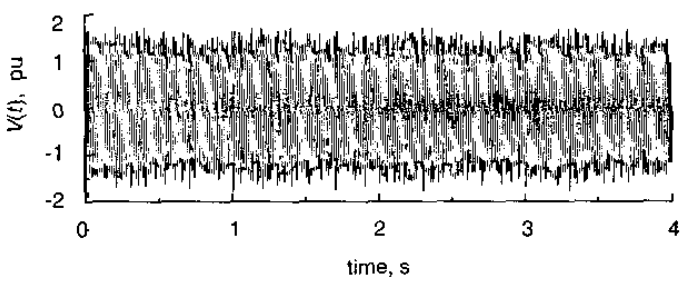

Fig. 6 The given toltage ficker waveform 
Table 1: Simulation cases for given voltage flicker waveform

\begin{tabular}{|c|c|c|c|c|c|c|c|}
\hline & $f_{s y s}, \mathrm{~Hz}$ & $N$ & $T(s)$ & $f_{s}$ (samples/s) & $h$ & $H$ & $M$ \\
\hline Case 1 & 60 & 128 & 4 & 7680 & 15 & 2048 & 30720 \\
\hline Case 2 & 60 & 64 & 8 & 3840 & 15 & 2048 & 30720 \\
\hline Case 3 & 60 & 32 & 16 & 1920 & 15 & 2048 & 30720 \\
\hline Case 4 & 60 & 64 & 4 & 3840 & 15 & 1024 & 15360 \\
\hline Case 5 & 60 & 32 & 8 & 1920 & 15 & 1024 & 15360 \\
\hline Case 6 & 60 & 16 & 16 & 960 & 15 & 1024 & 15360 \\
\hline Case 7 & 50 & 256 & 4 & 12800 & 25 & 2048 & 51200 \\
\hline Case 8 & 50 & 128 & 8 & 6400 & 25 & 2048 & 51200 \\
\hline Case 9 & 50 & 64 & 16 & 3200 & 25 & 2048 & 51200 \\
\hline Case 10 & 50 & 128 & 4 & 6400 & 25 & 1024 & 25600 \\
\hline Case 11 & 50 & 64 & 8 & 3200 & 25 & 1024 & 25600 \\
\hline Case 12 & 50 & 32 & 16 & 1600 & 25 & 1024 & 25600 \\
\hline
\end{tabular}

Table 2: Calculation results with 1-cycle period as a window

\begin{tabular}{|c|c|c|c|c|c|c|c|c|c|c|c|}
\hline$f_{n} \cdot \mathrm{Hz}$ & $\begin{array}{l}\Delta V_{-} n \\
1\end{array}$ & 6 & 10 & 15.25 & 17 & 20 & 23 & 25.75 & 30 & $\Delta V \%$ & $\Delta V 10 \%$ \\
\hline Given value & 10 & 10 & 10 & 10 & 10 & 10 & 10 & 10 & 10 & 30 & 20.71 \\
\hline Case 1 & 9.99 & 9.83 & 9.53 & 8.97 & 8.72 & 8.26 & 7.73 & 7.22 & 6.36 & 25.77 & 18.51 \\
\hline Case 2 & 9.97 & 9.83 & 9.52 & 8.96 & 8.7 & 8.27 & 7.74 & 7.22 & 6.35 & 25.76 & 18.50 \\
\hline Case 4 & 9.95 & 9.82 & 9.54 & 8.95 & 8.73 & 8.26 & 7.73 & 7.23 & 6.36 & 25.76 & 18.51 \\
\hline Case 5 & 9.96 & 9.84 & 9.52 & 8.94 & 8.71 & 8.27 & 7.75 & 7.23 & 6.36 & 25.76 & 18.50 \\
\hline Case 7 & 9.98 & 9.74 & 9.33 & 8.51 & 8.18 & 7.55 & 6.86 & 6.15 & 5.03 & 24.25 & 17.66 \\
\hline Case 8 & 9.97 & 9.76 & 9.33 & 8.52 & 8.18 & 7.56 & 6.84 & 6.16 & 5.03 & 24.26 & 17.67 \\
\hline Case 10 & 9.98 & 9.76 & 9.35 & 8.52 & 8.18 & 7.55 & 6.85 & 6.16 & 5.03 & 24.27 & 17.68 \\
\hline Case11 & 9.97 & 9.77 & 9.33 & 8.52 & 8.19 & 7.54 & 6.85 & 6.15 & 5.03 & 24.26 & 17.67 \\
\hline
\end{tabular}

resolution. There are twelve cases in Table 1 for comparison, where both $50 \mathrm{~Hz}$ and $60 \mathrm{~Hz}$ systems are considered. Fig 6 shows a given voltage flicker waveform, which has 1 pu average RMS value and contains $1 \mathrm{~Hz}, 6 \mathrm{~Hz}, 10 \mathrm{~Hz}$, $15.25 \mathrm{~Hz}, 17 \mathrm{~Hz}, 20 \mathrm{~Hz}, 23 \mathrm{~Hz}, 25.75 \mathrm{~Hz}$ and $30 \mathrm{~Hz}$ flicker components. Each flicker value is $0.1 \mathrm{pu}(10 \%)$ for the purpose of showing the calculation ability. The calculation results of the twelve cases have been carefully examined. While the others have serious leakage effects (side-lobes effect) in the FFT calculation, a few feasible cases are given in Table 2. However, it can be found that there are still obvious calculation errors for higher frequency components. It is observed that the higher the modulation frequency, the larger the error that occurs. The reason may be that the signal frequencies (modulation frequencies) are very close to the carrier frequency (power frequency) ,and so the $50 \mathrm{~Hz}$ system has larger errors.

To improve the frequency leakage effect, the data length used to calculate the RMS values is investigated. Since voltage flicker is fluctuation of voltage magnitude, another possible way to obtaining the RMS values may be to use sampled data in a half or quarter cycle only. This method is revealed in Fig. 7. The calculation results for a few feasible cases are given in Tables 3 and 4. There is significant improvement. Fig. 8 shows the comparison of demodulation results for case 4 . The method with half-cycle sampled data as a window is better because it has lower errors for modulation components under $17 \mathrm{~Hz}$. It has been reported

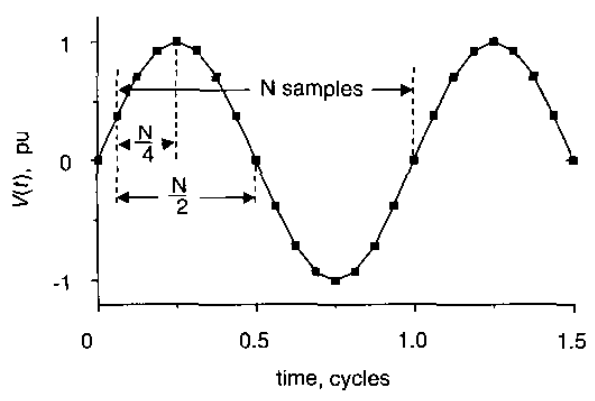

Fig. 7 Window size (number of data) used to calculate RMS values

that arc furnace loads usually produce lower frequency voltage flicker $[1-3]$, and the $6-10 \mathrm{~Hz}$ components are critical in the calculation of $\Delta V 10$. From Table 3 , case 4 is chosen for the $60 \mathrm{~Hz}$ system and case 10 for the $50 \mathrm{~Hz}$ system when both calculation accuracy and data length are considered. They are used for the following study.

To improve the calculation accuracy still further, a calibration method can be adopted in practical instrument designs. In this paper, the rectangular window method is used in the FFT process. It contains the narrowest mainlobe, and the widest side-lobe [19]. Therefore, all FFT calculations are carried out with limited data, which would cause a leakage effect. To reveal the effect, the attenuation 
Table 3: Calculation results with 1/2-cycle period as a window

\begin{tabular}{|c|c|c|c|c|c|c|c|c|c|c|c|}
\hline \multirow[b]{2}{*}{$f_{n}, \mathrm{~Hz}$} & \multicolumn{11}{|c|}{$\Delta V_{-n} \%$} \\
\hline & 1 & 6 & 10 & 15.25 & 17 & 20 & 23 & 25.75 & 30 & $\Delta V \%$ & $\Delta V 10 \%$ \\
\hline Given value & 10 & 10 & 10 & 10 & 10 & 10 & 10 & 10 & 10 & 30 & 20.71 \\
\hline Case1 & 10.0 & 9.96 & 9.88 & 9.75 & 9.67 & 9.55 & 9.39 & 9.26 & 9.00 & 28.84 & 20.12 \\
\hline Case 2 & 9.98 & 9.96 & 9.87 & 9.73 & 9.66 & 9.56 & 9.4 & 9.25 & 9.00 & 28.82 & 20.11 \\
\hline Case 4 & 9.97 & 9.95 & 9.89 & 9.73 & 9.68 & 9.56 & 9.39 & 9.27 & 9.01 & 28.83 & 20.12 \\
\hline Case 5 & 9.98 & 9.97 & 9.87 & 9.71 & 9.66 & 9.56 & 9.41 & 9.26 & 9.01 & 28.83 & 20.11 \\
\hline Case 7 & 9.99 & 9.93 & 9.83 & 9.61 & 9.52 & 9.35 & 9.16 & 8.93 & 8.57 & 28.33 & 19.86 \\
\hline Case 8 & 9.99 & 9.95 & 9.83 & 9.62 & 9.53 & 9.36 & 9.14 & 8.94 & 8.57 & 28.34 & 19.87 \\
\hline Case10 & 9.99 & 9.94 & 9.85 & 9.62 & 9.52 & 9.35 & 9.15 & 8.93 & 8.58 & 28.34 & 19.87 \\
\hline Case 11 & 9.98 & 9.96 & 9.83 & 9.61 & 9.53 & 9.33 & 9.15 & 8.93 & 8.58 & 28.33 & 19.87 \\
\hline
\end{tabular}

Table 4: Calculation results with $1 / 4-c y c l e$ as a window

\begin{tabular}{|c|c|c|c|c|c|c|c|c|c|c|c|}
\hline$f_{n}, \mathrm{~Hz}$ & $\begin{array}{l}\Delta V_{-n} \% \\
1\end{array}$ & 6 & 10 & 15.25 & 17 & 20 & 23 & 25.75 & 30 & $\Delta V \%$ & $\Delta \vee 10 \%$ \\
\hline Given value & 10 & 10 & 10 & 10 & 10 & 10 & 10 & 10 & 10 & 30 & 20.71 \\
\hline Case 1 & 9.71 & 9.71 & 9.68 & 9.66 & 9.64 & 9.60 & 9.55 & 9.52 & 9.46 & 28.84 & 19.97 \\
\hline Case2 & 9.76 & 9.61 & 9.56 & 9.65 & 9.76 & 9.61 & 9.55 & 9.51 & 9.45 & 28.82 & 19.91 \\
\hline Case 4 & 9.75 & 9.61 & 9.58 & 9.64 & 9.78 & 9.61 & 9.55 & 9.53 & 9.47 & 28.84 & 19.93 \\
\hline Case 5 & 9.77 & 9.67 & 9.58 & 9.63 & 9.76 & 9.62 & 9.59 & 9.53 & 9.43 & 28.86 & 19.95 \\
\hline Case 7 & 9.72 & 9.70 & 9.67 & 9.61 & 9.59 & 9.55 & 9.50 & 9.43 & 9.32 & 28.70 & 19.89 \\
\hline Case 8 & 9.72 & 9.76 & 9.67 & 9.62 & 9.60 & 9.56 & 9.48 & 9.44 & 9.33 & 28.73 & 19.92 \\
\hline Case 10 & 9.71 & 9.75 & 9.69 & 9.62 & 9.59 & 9.55 & 9.49 & 9.43 & 9.34 & 28.73 & 19.92 \\
\hline Case11 & 9.69 & 9.76 & 9.67 & 9.61 & 9.59 & 9.52 & 9.48 & 9.42 & 9.33 & 28.69 & 19.91 \\
\hline
\end{tabular}

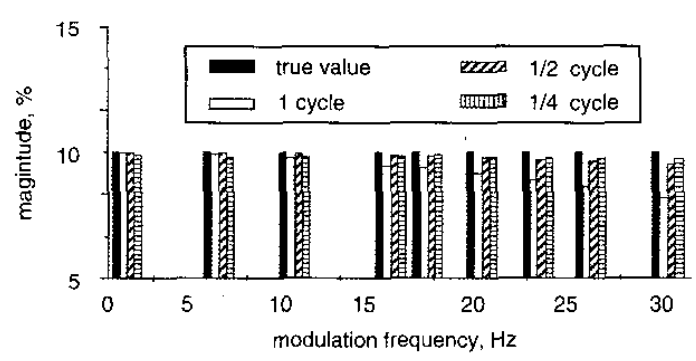

Fig. 8 Effect of window size on ficker calculation

factor is defined as

$$
G_{A}\left(f_{n}\right)=\frac{\text { calculated } \Delta V_{\lrcorner}}{\text {given } \Delta V_{\lrcorner}}
$$

To obtain attenuation factor values, the IDDM is repeated for 30 voltage waveforms. Each waveform has only one modulation component, i.e. $f_{\mathfrak{n}}=1,2, \ldots, 29$ or $30 \mathrm{~Hz}$, respectively, for each waveform, and $\Delta V_{n}=10 \%$. The attenuation factor curve of the case 4 system is given in Fig. 9. It is found that the curve is smooth. The leakage effect is more serious in higher frequency components.

To recover the leakage, a calibration factor $\left(G_{C}\right)$ should give the result as

$$
G_{C}\left(f_{n}\right) G_{A}\left(f_{n}\right)=1
$$

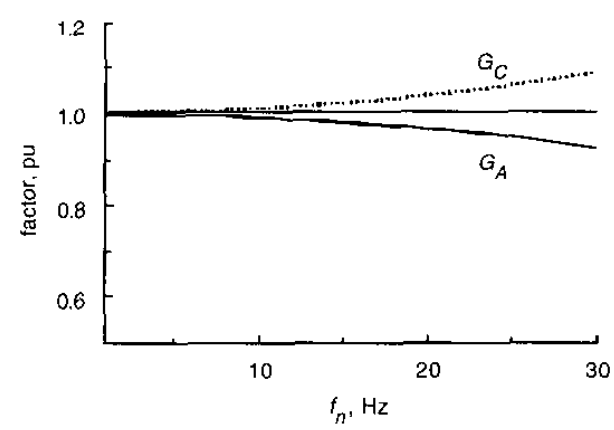

Fig. 9 The attenuation factor and calibration factor curves for case 4

To calibration factors of modulation components, $f_{n}=1$, $2, \ldots, 29$ and $30 \mathrm{~Hz}$, can be obtained by the reciprocals of the corresponding attenuation factors. However, since the modulation frequencies in a real voltage flicker waveform can be non-integer, a regression function should be used. The regression analysis method uses the least square error criteria [20]. In this paper a sixth-order polynomial is used to approximate the calibration factor curve as given in Fig. 9, which is also smooth.

The calculated $f_{13} \mathrm{~Hz}$ amplitude modulation component in (9) is multiplied by its corresponding calibration factor to 
Table 5: Comparison of calculation results with and without calibration

\begin{tabular}{|c|c|c|c|c|c|c|c|}
\hline & & \multirow[t]{2}{*}{$f_{n}, \mathrm{~Hz}$} & \multirow[t]{2}{*}{ Given value } & \multicolumn{2}{|c|}{ Without calibration } & \multicolumn{2}{|c|}{ With calibration } \\
\hline & & & & Case 4 & Case 10 & Case 4 & Case 10 \\
\hline & \multirow[t]{9}{*}{$\Delta V_{-n} \%$} & 1 & 10 & 9.97 & 9.98 & 9.97 & 9.99 \\
\hline & & 6.5 & 10 & 9.95 & 9.93 & 9.99 & 10 \\
\hline & & 10 & 10 & 9.89 & 9.83 & 10 & 10 \\
\hline & & 15.25 & 10 & 9.73 & 9.61 & 9.99 & 9.99 \\
\hline & & 17 & 10 & 9.68 & 9.53 & 10.01 & 10 \\
\hline & & 20.25 & 10 & 9.55 & 9.33 & 10.01 & 9.99 \\
\hline & & 23.5 & 10 & 9.36 & 9.11 & 9.98 & 10 \\
\hline & & 25.75 & 10 & 9.27 & 8.93 & 10.01 & 9.99 \\
\hline & & 30 & 10 & 9 & 8.59 & 10 & 10.01 \\
\hline$\Delta V, \%$ & & & 30 & 28.82 & 28.312 & 29.99 & 29.99 \\
\hline$\Delta V 10, \%$ & & & 20.78 & 20.2 & 19.94 & 20.78 & 20.78 \\
\hline
\end{tabular}

Table 6: Effect of harmonics on flicker calculation

\begin{tabular}{|c|c|c|c|c|c|c|c|c|}
\hline & \multirow[t]{2}{*}{$f_{n}, \mathrm{~Hz}$} & \multirow[t]{2}{*}{ Given value } & \multicolumn{3}{|c|}{$60 \mathrm{~Hz}$ system } & \multicolumn{3}{|c|}{$50 \mathrm{~Hz}$ system } \\
\hline & & & Case A & Case B & Case C & Case D & Case E & Case F \\
\hline \multirow[t]{9}{*}{$\Delta V_{-n} \%$} & 1 & 10 & 10.05 & 9.99 & 10.03 & 10.03 & 10 & 10.03 \\
\hline & 6 & 10 & 10.03 & 9.99 & 10.03 & 10.02 & 10 & 10.04 \\
\hline & 10 & 10 & 10.02 & 10.01 & 10.02 & 10 & 9.99 & 10.04 \\
\hline & 15.25 & 10 & 10.03 & 9.99 & 10.01 & 10.02 & 10.02 & 10.04 \\
\hline & 17 & 10 & 10.02 & 10 & 10.04 & 10.01 & 10.03 & 10.02 \\
\hline & 20 & 10 & 10.03 & 10.02 & 10.02 & 10.02 & 10.03 & 10.07 \\
\hline & 23 & 10 & 10.04 & 10.02 & 10.04 & 10.03 & 10.01 & 10.05 \\
\hline & 25.75 & 10 & 10.03 & 10.01 & 10.01 & 10.01 & 10.03 & 10.03 \\
\hline & 30 & 10 & 10.03 & 10.01 & 10.04 & 10.04 & 10.04 & 10.06 \\
\hline$\Delta V, \%$ & & 30 & 30.09 & 30.01 & 30.08 & 30.06 & 30.05 & 30.13 \\
\hline$\Delta \vee 10, \%$ & & 20.71 & 20.77 & 20.71 & 20.76 & 20.74 & 20.73 & 20.79 \\
\hline
\end{tabular}

Table 7: Effect of power frequency shifting on flicker calculation

\begin{tabular}{|c|c|c|c|c|c|c|c|c|c|c|}
\hline & \multirow[t]{2}{*}{$f_{n}, \mathrm{~Hz}$} & \multirow[t]{2}{*}{ Given Value } & \multicolumn{4}{|c|}{$60 \mathrm{~Hz}$ system } & \multicolumn{4}{|c|}{$50 \mathrm{~Hz}$ system } \\
\hline & & & Case G & Case H & Case I & Case J & Case K & Case L & Case M & Case N \\
\hline \multirow[t]{9}{*}{$\Delta V_{-n}, \%$} & 1 & 10 & 10.01 & 9.99 & 9.99 & 10.01 & 9.99 & 10.02 & 10 & 10 \\
\hline & 6 & 10 & 9.99 & 9.99 & 10.01 & 10.01 & 10.01 & 10 & 10 & 10 \\
\hline & 10 & 10 & 10 & 9.98 & 9.99 & 10 & 9.99 & 9.99 & 10 & 10.01 \\
\hline & 15.25 & 10 & 9.97 & 9.98 & 10.01 & 10.02 & 10 & 10.01 & 10 & 9.97 \\
\hline & 17 & 10 & 9.99 & 10 & 10 & 9.99 & 9.99 & 10 & 10 & 9.99 \\
\hline & 20 & 10 & 9.98 & 10.01 & 9.99 & 10 & 9.97 & 10 & 10.01 & 9.99 \\
\hline & 23 & 10 & 9.95 & 9.99 & 10 & 10 & 9.99 & 9.98 & $10 . .01$ & 10 \\
\hline & 25.75 & 10 & 10 & 10 & 9.99 & 9.98 & 9.99 & 10.01 & 9.99 & 9.99 \\
\hline & 30 & 10 & 9.97 & 10.01 & 10.02 & 10.01 & 9.97 & 10 & 9.99 & 9.98 \\
\hline$\Delta V, \%$ & & 30 & 29.95 & 29.98 & 30 & 30.01 & 29.97 & 30 & 30 & 29.98 \\
\hline$\Delta V 10, \%$ & & 20.71 & 20.68 & 20.69 & 20.71 & 20.72 & 20.69 & 20.71 & 20.71 & 20.7 \\
\hline
\end{tabular}

obtain the modified value. Table 5 shows the calculation results and the comparison of $\Delta V$ and $\Delta V 10$ of the given flicker waveforms without and with calibration. The errors have greatly improved.

\section{Effect of harmonics and frequency shifting}

Not only DC arc furnaces, but also AC arc furnaces will produce harmonic currents and cause harmonic-distorted 
voltage waveforms. The voltage flicker values of waveforms with harmonic distortion need to be calculated. The size of $\mathrm{AC}$ and $\mathrm{DC}$ arc furnaces in a $161 \mathrm{kV}$ customer could be as large as $100 \mathrm{MW}$. Operation of arc furnaces would also cause frequency shifting in a weak power system. This phenomenon is obvious in an island power system, such as Taiwan. For a digital voltage flicker meter, the effect of power frequency shifting should be considered.

The test voltage flicker waveform in Fig. 6 is also used. Both integral and non-integral harmonics are considered. Several cases are chosen for comparison.

Case A: with 0.05 pu fifth- and seventh-order harmonics, $f_{s y s}=60 \mathrm{~Hz}$

Case B: with $0.05 \mathrm{pu} 187 \mathrm{~Hz}$ harmonic, $f_{s y s}=60 \mathrm{~Hz}$

Case C: with 0.05 pu fifth- and seventh-order and $187 \mathrm{~Hz}$ harmonics, $f_{s y s}=60 \mathrm{~Hz}$

Case D: with 0.05 pu fifth- and seventh-order harmonics, $f_{s y s}=50 \mathrm{~Hz}$

Case E: with $0.05 \mathrm{pu} 187 \mathrm{~Hz}$ harmonic, $f_{s y s}=50 \mathrm{~Hz}$

Case F: with $0.05 \mathrm{pu}$ fifth- and seventh-order and $187 \mathrm{~Hz}$ harmonics, $f_{\text {sy:s }}=50 \mathrm{~Hz}$

Case G: $f_{\text {sis }}=60.1 \mathrm{~Hz}$

Case $\mathrm{H}: f_{s y \mathrm{~s}}=60.5 \mathrm{~Hz}$

Case I: $f_{s y s}=59.9 \mathrm{~Hz}$

Case $\mathrm{J}: f_{s, s}=59.5 \mathrm{~Hz}$

Case $\mathrm{K}: f_{s y s}=50.1 \mathrm{~Hz}$

Case L: $f_{s y s}=50.5 \mathrm{~Hz}$

Case M: $f_{\text {sys }}=49.9 \mathrm{~Hz}$

Case N: $f_{s y \mathrm{x}}=49.5 \mathrm{~Hz}$

While Table 6 shows the effect of harmonics on flicker calculation, the effect of power frequency shifting is revealed in Table 7. These effects are not significant. The calculation results of $\Delta V$ and $\Delta V 10$ are still very close to their given values.

\section{Application to field measurement waveforms}

To apply the above method to practical systems, the measurement data from the arc furnace feeders of customers of a $60 \mathrm{~Hz}$ system are used. The sampling rate is 64 samples per cycle ( 3840 samples/s). Figs. $10 a$ and $10 b$, respectively, show the voltage waveforms of $\mathrm{DC}$ arc furnace and $\mathrm{AC}$ arc furnace feeders inside steel plants. Since the DC arc furnace uses a constant-current control mode, its voltage flicker is not serious, but there is harmonic distortion. However, the voltage flicker problem is much more severe in the $\mathrm{AC}$ arc furnace. The system frequency at the $\mathrm{DC}$ arc furnace feeder is $59.97 \mathrm{~Hz}$, and that at the $\mathrm{AC}$ furnace feeder is $59.894 \mathrm{~Hz}$. The calculation results of $\Delta V$ and $\Delta V 10$ are given in Table 8 , where three cases are compared. Since the 1-cycle window method without calibration is inferior, the calculated values are low due to the leakage effect. The $1 / 2$-cycle window method with calibration should give the most accurate values. The flicker components are also
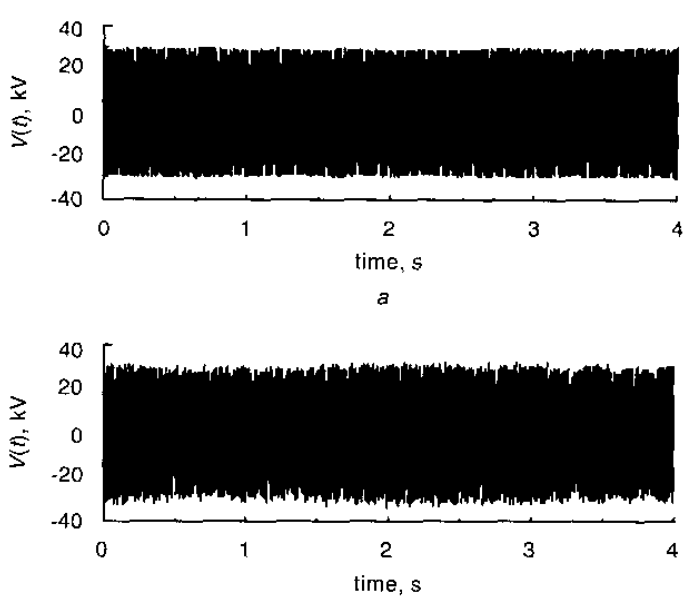

$b$

Fig. 10 Field measurement voltage flicker waveforms $a$ DC furnace (light voltage flicker) $b$ AC furnace (severc voltage flicker)
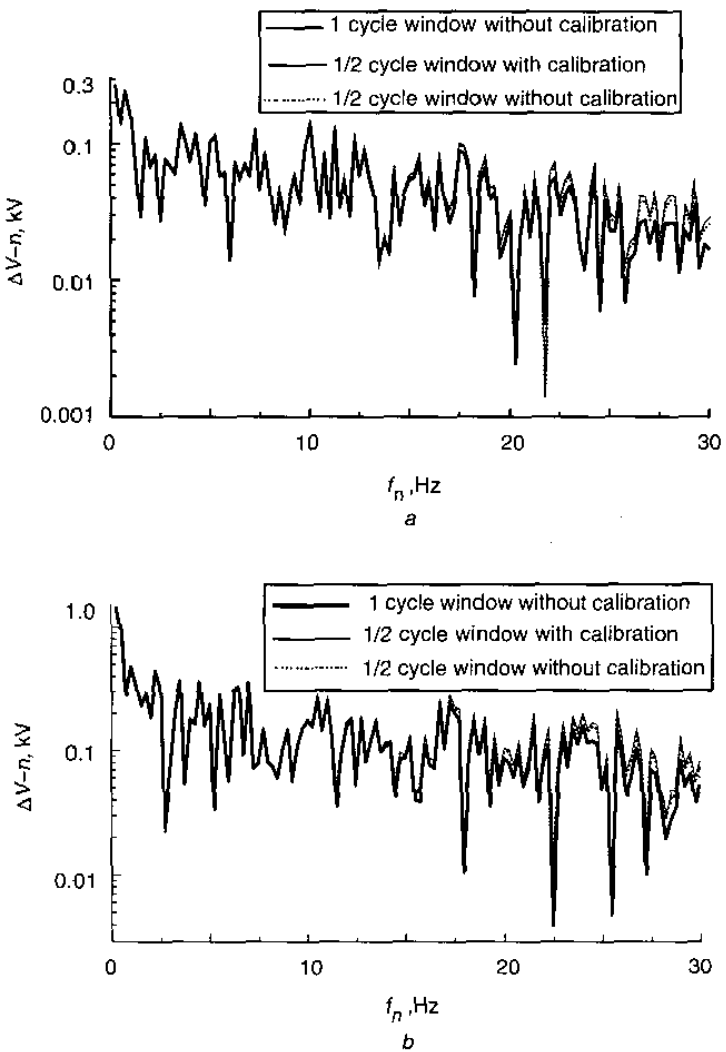

Fig. 11 Calculation results of ficker components in field measurement waveforms

$a \mathrm{DC}$ arc furnace

$b \mathrm{AC}$ arc furnace

Table 8: Calculation results of field measurement voltage flicker waveforms

\begin{tabular}{|c|c|c|c|c|c|c|}
\hline & \multicolumn{2}{|c|}{ 1-cycle window without calibration } & \multicolumn{2}{|c|}{$1 / 2$-cycle window without calibration } & \multicolumn{2}{|c|}{$1 / 2$-cycle window with calibration } \\
\hline & DC furnace & AC furnace & DC furnace & $A C$ furnace & DC furnace & AC furnace \\
\hline$\Delta V, \%$ & 3.7 & 10.38 & 3.85 & 10.65 & 3.90 & 10.75 \\
\hline$\Delta V, 10 \%$ & 2.45 & 5.23 & 2.57 & 5.48 & 2.62 & 5.57 \\
\hline
\end{tabular}


shown in Fig. 11. The differences are obvious in the higherfrequency components.

\section{Conclusions}

This paper has presented an effective method of calculating flicker components, which has greatly reduced the leakage effect in FFT and increased the calculation accuracy. Since higher amplitude modulation frequencies are close to the power frequency, they have larger calculation errors if the original indirect demodulation method is used. Both window size and calibration are investigated to reduce the calculation errors. From the calculation results of the given voltage flicker waveform and field measured waveforms, the proposed method has given satisfactory accuracy. This method can be used in both $50 \mathrm{~Hz}$ and $60 \mathrm{~Hz}$ systems. The effects of harmonics and power frequency shifting are negligible.

\section{Acknowledgments}

This paper has been supported partly by the National Science Council of ROC under grant NSC 90-2213-E-011064 .

\section{References}

1 Bhargava, B.: 'Arc furnace flicker measurements and control', IEEE Trans. Power Deliv., 1993, 8, (1), pp. 400-410

2 Montanari. G.C., Loggini, M., Cavallini, A., Pitti, L., and Zaninelli, D.: 'Arc-furnace model for the study of flicker compensation in electrical network', IEEE Trans. Pover Deliv., 1994, 9, (4), pp. 20262036

3 Manchur, G., and Erven, C.C.: 'Development of a model for prediction flicker from electric arc furnaces', IEEE Trans: Power Deliv., 1992, 7, (1), pp. 416-426
$4 \mathrm{Wu}, \mathrm{C.J}$.: 'Effect of high voltage side voltage flicker sources on low voltage side customers'. Research report, Power Research Institute. Taiwan Power Company, Taipei, Taiwan. 1994

$5 \mathrm{Wu}, \mathrm{C} . J$. , and Lce, L.H.: 'Electric power quality evaluation of $161 \mathrm{kV}$ large size steel plants". Research report, Power Research Institute, Tawan Power Company, Taipei, Taiwan, 1995

6 Heydt, G.T.: 'Electric power quality', (Stars in a Circle Publications. USA, 1994)

7 IEEE Standard 519-1992, 'IEEE recommended practices and reequirements for harmonic control in electrical power system'. New Jersey, 1993

8 IEC 61000-3-3, 'Electromagnetic compatibility (EMC), part 3: LimitsSection 3: Limitation of voltage fluctuations and flicker in low-voltage power supply systems for equipment with rated current $\leq 16 \AA^{\text {' }}$ 1994

9 IEC 61000-3-5. 'Electromagnetic compatibility (EMC), part 3: LimitsSection 5: Limitation of voltage fluctuations and ficker in low-voitage power supply systems for equipment with rated current greater than $6 \mathrm{~A}^{\prime} 1994$

10 Chen, M.T.: 'Digital algorithms for measurement of voltage flicker", IEE Proc., Gener. Transm. Distrib., 1997, 144, (2), pp. 175-180

11 Nuccio, S.: 'A digital instrument for measurement of voltage flicker'. Proc. of IEEE Conf. on Instrumentation and measurement technology, Ottawa, Canada, May 1997, pp. 281-284

12 UIE, 'Flicker Measurement and Evaluation', International Union of Electroheat, Paris, France, 1992

13 Instruction Manual, 'Analog-Digital Hybrid Type UIE Flickermeter', Fukuoka Denki-Keiki Co., Fukuoka, Japan, 1993

14 Taiwan Power Company, "Voltage flicker temporary limitation standard', Taiwan Power Company, Taipei, Taiwan, 1995

15 Chang. W.N., Wu, C.J., and Yen, S.S.: 'A flexible voltage ficker teaching facility for electric power quality education;, IEEE Trans. Power Syst., 1998, 13, (1), pp. 27-33

16 Nendis, S.R., Bishop, M.T., Do, A.V. and Boyd, D.M.: 'Investigation of transmission system voltage flicker due to multiple ac and $\mathrm{dc}$ furnace operations, IEEE Trans. Power Deliv., 1995, 10, (1), pp. 483496

17 Oppenheim, A.V.. Willsky, A.S., and Young, I.T.: 'Signals and systems', (Prentice-Hall, Inc., New Jersey, 1983)

18 McClellan, J.H., Schafer, R.W., and Yoder, M.A.: 'DSP first: a multimedia approach', (Prentice-Hail, Inc., New Jersey, 1999)

19 Oppenheim, A.V., Schafer. R.W., and Buck, J.R.: 'Discrete-time signal processing," 2nd Edn. (Prentice-Hall, Inc., New Jersey, 1999) 20 Milton, J.S. and Amold. J.C.: 'Probability and statistics in the engineering and and computing sciences', (McGraw-Hill, New York, USA, 1986) 